memo (2011) Vol. 4: 140-141

DOI 10.1007/s12254-011-0276-1

Printed in Austria

(C) Springer-Verlag 2011

\title{
Long-term results of national treatment trials in childhood acute lymphoblastic leukaemia in several Middle/East European countries
}

\section{J. Starý}

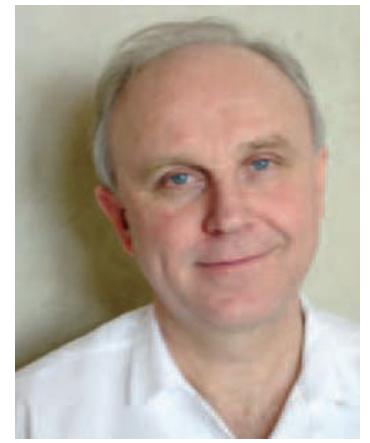

Jan Starý, M.D.

2nd Faculty of Medicine, Department of Pediatric Hematology and Oncology, Charles University and University Hospital Motol, Prague, Czech Republic

Received 1 February 2011; accepted 8 March 2011

\section{Introduction}

Acute lymphoblastic leukaemia (ALL) is the most frequent childhood cancer. During the last 50 years its prognosis has improved from zero probability of survival in the 1950 s to more than $80 \%$ chance to be cured at the

Correspondence: Jan Starý, M.D., Prague, Department of Pediatric Hematology and Oncology, University Hospital Motol, Vúvalu 84, 15006 Prague 5, Czech republic.

E-mail: jan.stary@lfmotol.cuni.cz beginning of the 21st century. ALL is a highly chemosensitive disease and its successful treatment is a good indicator of the level of medical care that children with cancer get in each country. There are huge differences in the outcome of this disease between developed and developing countries.

The international randomized multicenter trial Acute Lymphoblastic Leukaemia Intercontinental - BFM 2002 (ALL IC) is one of the most successful projects developed recently inside the International-BFM- Study Group (I-BFM-SG) - one of the world-leading societies connecting national leukaemia groups in Europe and abroad. Fourteen countries from Europe, South America and Asia took part in a trial running between 
2002 and 2007. Amongst them, Poland, Czech Republic, Slovakia, Hungary, Slovenia, Croatia and Serbia represented Middle/East Europe. The majority of countries participating in this trial improved their treatment results in comparison with previous national studies. For some of them it was a first experience with participation in an international randomized trial using a common database. The final results of this study will be published in a near future.

Several Middle/East European countries participating in trial ALL IC-BFM 2002 accepted the invitation to present their pre-ALL IC experience in the diagnosis and treatment of childhood ALL in MEMO journal published according to a common concept. Historically, paediatric oncologists from East-European countries suffered from a lack of contact with their West-European colleagues during long-lasting communist rule in this part of Europe. During these difficult years of life in totalitarian systems they had limited access to the medical information about new diagnostic and treatment modalities. Despite relatively good standard of general paediatrics in some of these countries, the paediatric oncology generally suffered from lack of financial resources not only for research and expensive diagnostic procedures, but more importantly also for the purchase of the expensive anticancer drugs, antibiotics etc. Middle/East Europe is composed of a very heterogeneous group of countries. Despite sharing many similarities, it is certainly true that the starting point was very different for the individual countries at the beginning of the1990s after the end of communism in this part of Europe. According to Eurocare data, the probability of 5-yr overall survival of children with cancer was significantly lower in East Europe (45-65\%) in comparison with West Europe (5-yr OS 71-81\%) in the first half of the 1990s [1]. The recent survey of the SIOPE Board (European branch of the International Paediatric Oncology Society) showed that entry into clinical trials was more consisten in Western rather than in Eastern European countries in the 1990s. EastEuropean paediatric oncologists suffered from lack of experience in performing controlled clinical studies, lack of health professionals trained in Good Clinical Practice. Great reduction of mortality has been achieved in the 1990s and at the beginning of the 21st century in the Eastern European countries. Further improvement will be slower and a necessary infrastructure for it has to be established. Multi-disciplinary skilled teams have to be built and equipped. They are required for the complex care of childhood cancer patients and to warrant further improvements in survival.

Papers coming from Poland [2], Czech Republic [3], Slovakia [4], Slovenia [5] and Serbia [6] will introduce the history of nationally unified treatment of childhood ALL in each country before the ALLIC study has been launched. Despite all difficulties, the paediatric oncologists have done their best to give chance of cure to children with ALL also in this part of Europe. I am sure the readers will agree on it.

Conflict of interest

The author declares that there is no conflict of interest.

\section{References}

[1] Steliarova-Foucher E, Stiller C, Kaatsch P, et al. Geographical patterns and time trends of cancer incidence and survival among children and adolescents in Europe since the 1970s (the ACCIS project): an epidemiological study. Lancet, 364: 2097-2105, 2004.

[2] Derwich K, et al. Comparison of long-term results in children with standard risk acute lymphoblasic leukemia. memo, 4(3): 184-189, 2011.

[3] Stary J, et al. History of treatment and long-term outcome in children with ALL in the Czech Republic. memo, 4(3): 196-202, 2011.

[4] Kaiserova E, et al. Results of acute lymphoblastic leukemia treatment in the Slovak Republic. memo, 4(3): 190-195, 2011.

[5] Avcin S, et al. History of treatment and long-term outcome of childhood ALL in Slovenia. memo, 4(3): 178-185, 2011.

6] Janic D, et al. History of treatment and long-term outcome in children with acute lymphoblastic leukemia in Serbia. memo, 4(3): 174-177, 2011. 